\title{
A Apropriação nos novos media e a (I)maturidade dos videojogos
}

\author{
Filipe Costa Luz
}

\begin{abstract}
Resumo
O potencial criativo de determinados suportes analógicos e digitais é frequentemente subjugado no processo de desenvolvimento artístico de jogos, sendo ignorado em muitos cursos de formação que frequentemente se orientam para a estratégia comercial de apresentarem ofertas no contexto de novas tecnologias ou produtos. Este trabalho é então uma análise de como alguns exemplos de jogos procuram referências noutros medias para se posicionarem de uma forma disruptiva, procurando uma elegância visual, novas mecânicas de jogo e não apenas uma apropriação de processos de produção já mais consolidados na industria de entretenimento. Propomos nas referências dos jogos Framed (Loveshack, 2014), Old Man Journey (Broken Rules, 2017), Serial Cleaner (Curve Digital Games) ou Monument Valley (Ustwo Games, 2014), procurar relações com outros medias mais reconhecidos no universo das artes, como a banda desenhada ou a animação, para evidenciar uma estratégia criativa que pretende ser alternativa no enquadramento actual do desenvolvimento de jogos.
\end{abstract}

Palavras-chave:

animação; videojogos; media; apropriação. 


\section{New media appropriation and videogames (im)maturity}

Abstract: The creative potential of analog and digital media is often subjugated in the process of artistic game development and ignored in many training courses that are focus on the commercial strategy to present the curricula in the context of new technologies and products. This work is an analysis of how some game examples seek references in other media to position themselves in a disruptive way, looking for a visual elegance, new game mechanics and not only on an appropriation of entertainment industry production processes. We propose through the references of the games Framed (Loveshack, 2014), Old Man Journey (Broken Rules, 2017), Serial Cleaner (Curve Digital Games) or Monument Valley (Ustwo Games, 2014), to seek for relations with other media more recognized in the universe of the arts, such as comics and animation, to highlight a creative strategy that aims to be disruptive in game development.

Keywords: animation; videogames; media; appropriation.

\section{L’appropriation dans les nouveaux médias et (i)mmaturité des jeux vidéo}

Résumé: Le potentiel créatif de certains médias analogiques et numériques est souvent subjugué dans le processus artistique de développement des jeux, ignorés en général pour de nombreux cours de formation qui sont souvent orientés pour une stratégie commerciale de soumettre des offres dans le cadre des nouvelles technologies ou produits. Ce travail est donc une analyse de la façon comment quelques exemples de jeux cherchent des références dans d'autres médias pour se positionner de une manière perturbatrice, à la recherche d'une élégance visuelle, nouvelles mécaniques de jeu et non pas seulement une appropriation des processus de production plus consolidés dans l'industrie du divertissement. Nous vous proposons dans les références des jeux Frame (Loveshack, 2014), Old Man Journey (Broken Règles, 2017), Serial Cleaner (Curve Jeux numériques) ou Monument Valley (Ustwo Games, 2014), chercher des relations avec d'autres médias les plus reconnus dans le monde des arts tels que la bande dessinée ou l'animation, pour montrer une stratégie créative qui vise être une alternative dans le cadre actuel de développement des jeux.

Mots-clés: animation; jeux vidéo; médias; appropriation.

\section{La apropiación en los nuevos medios y la (i)nmadurez de los videojuegos}

Resumen: El potencial creativo de determinados soportes analógicos y digitales es a menudo subyugado en el proceso de desarrollo artístico de juegos, siendo ignorado en muchos cursos de formación que a menudo se orientan hacia la estrategia comercial de presentar ofertas en el contexto de nuevas tecnologías o productos. Este trabajo es entonces un análisis de cómo algunos ejemplos de juegos buscan referencias en otros medios para posicionarse de forma disruptiva, buscando una elegancia visual, nuevas mecánicas de juego y no sólo una apropiación de procesos de producción ya consolidados en la industria del entretenimiento. En las referencias de los juegos Framed (Loveshack, 2014), Old Man Journey (Broken Rules, 2017), Serial Cleaner (Curve Digital Games) o Monument Valley (Ustwo Games, 2014), buscar relaciones con otros medios más reconocidos en el universo de las artes como el cómic o la animación, para evidenciar una estrategia creativa que pretende ser disruptiva en el actual marco del desarrollo de juegos.

Palabras clave: animación; videojuegos; media; apropiación. 


\section{Introdução}

No desenvolvimento tecnológico de jogos ou outros simuladores digitais, há uma curiosa obsessão em eliminar a presença visível do pixel com o argumento de ser uma necessidade para uma maior imersão no espaço de jogo. Mais uma vez, verifica-se a incessante busca técnica para iludir a real natureza do digital, escondendo a técnica, mimetizando processos analógicos ou o próprio mundo real, no que Gruisin e Bolter indicaram como dupla lógica de Remediação. Compreendemos este investimento, aceitamo-lo, mas gostaríamos de destacar neste trabalho o que o digital nos oferece como característica principal - o pixel e a sua opacidade.

Desde a "bola de ténis com aspecto rectangular" do Pong (Atari, 1972) ou das formas geométricas do Tetris (Alexey Pajitnov, 1984) que o pixel esteve sempre muito presente. Se nesse período a sua fundamentação derivava de muitas limitações técnicas, que hoje são progressivamente mais inexistentes, acabamos por verificar a estética trend em vários jogos, ilustrações ou animações que exploram criativamente o pixel como uma linguagem artística.

O investimento numa arte de mosaico em pixels de paletes de cores limitadas em diversos jogos da actualidade, contrastam assim com a tendência mais massificada do desenvolvimento tecnológico de jogos mainstream e parece ser precisamente esta estranheza de um regressar ao passado que atraiu os criadores de Minecraft (Mojang, 2011), Fez (Polytron Corporation, 2012) ou Hotline Miami (Abstraction Games/Dennatation Games, 2012).

\section{Apropriação nos novos media}

Nenhum projecto começa de uma folha em branco. O ambiente que nos rodeia, o momento que vivenciamos já é em sim mesmo um factor de diferenciação que nos coloca num determinado ponto de partida. Muitas das empresas de jogos que procuram se distinguir no mercado através da criação de produtos alternativos, apresentam estratégias curiosas para se demarcarem da concorrência massificada. Paradoxalmente, uma das estratégias criativas para uma abordagem diferente é precisamente copiar e fazê-lo de forma descarada.

A história já nos demonstrou por diversas vezes que a originalidade pode surgir através de uma reposição, apropriação ou repetição. Veja-se como Andy Warhol reforça a proposta dos ready made de Duchamp para compulsivamente os repetir e serializar numa dominante cultura de massas (Marques, 2007: 16). O facto de um artista se apropriar de uma obra para criar um novo conteúdo prova também que qualquer produto não se circunscreve em fronteiras definidas. Há todo um novo território a explorar pela criatividade que podem dar novos significados a objectos concebidos para uma determinada função. 
O jogo Monument Valley (Ustwo Games, 2014) é um curioso exemplo de apropriação de um delegado muito importante que M. C. Escher nos deixou. Em simples mecânicas de point and click, comandamos um avatar por um reino de ilusões ópticas através do qual imergimos num espaço elegantemente desafiador. Através de paletes de cor complementares e triádicas jogamos num espaço de design gráfico sofisticado, matematicamente incongruente, mas possível graças às ilusões de Escher.

Por esta razão, parece-nos muito interessante o facto de que qualquer obra ser aparentemente o resultado da apropriação de muitas outras, seja a nível conceptual, tecnológico ou formal. E se a uma nova obra o autor declarar visualmente as próprias referências, ainda se torna mais interessante para o espectador essa associação. Ora, no domínio das artes, qualquer referência com o passado é um óptimo ponto de partida. Veja-se como inclusive o próprio Marinetti, no seu famoso manifesto futurista, pretensiosamente disruptivo, faz a seguinte referência elogiosa ao passado indicando que «Vocês querem, pois, desperdiçar todas as suas melhores forças nesta eterna e inútil admiração do passado, da qual vocês só podem sair fatalmente exaustos, diminuídos e pisados?»1 (Filippo T. Marinetti, 1909).

Os videojogos não são diferentes, sendo clara a apropriação de cinema verificada pelas sistemáticas reproduções de convenções, linguagens, técnicas ou processos de pós-produção (Therrien, 2008: 243). Facilmente demonstrável em trailers de jogos, introduções cinematográficas, cinematics, entre outros. No caso de Framed (Loveshack, 2014) a banda desenhada serve como tema adaptado para a construção de mecânicas e o género noir reflecte-se na estética visual e cinematográfica da acção, na qual um detective tenta escapar de página em página. De muitos exemplos a que poderíamos recorrer, verificamos que a apropriação é um processo de enraizamento cultural, artístico, criativo e essencial para a produção de projectos onde, paradoxalmente, se pretende por vezes uma maior demarcação no estado da arte. Lars Konzack reforça esta ideia ao salientar que os jogos independentes procuram nos géneros, estilos e tecnologias que hoje não são consideradas mainstream para inovarem e se posicionarem de forma alternativa aos jogos mais massificados no mercado (Konzack, 2008: 200). Veja-se como algumas empresas estrategicamente investem em jogos de estética ilustrada em 2D, mais fáceis de produzir e nas quais o erro gráfico pode ser aceite ou utilizado como uma própria expressão artística. Os overlays das camadas de efeitos visuais do jogo Old Man Journey são assumidamente desalinhados com o espaço do cenário, o que reforça uma estética própria do domínio da animação tradicional e, por conseguinte, uma interessante estranheza na imperfeição que é tão repetidamente escondida nos jogos mainstream.

Os filmes a preto e branco, a animação 2D não são estéticas obsoletas, mas sim historicamente reconhecidas no universo da cultura visual. No design gráfico a perfeição de uma impressão digital contrasta com o erro provocado na impressão em serigrafia 
e risografia, contudo as imperfeitas texturas, cores ou formas, oferecem uma sensação nostálgica a mais velhas gerações, mas também um meio alternativo para aqueles que nasceram na era digital e desconhecem por completo os processos analógicos.

Parece-nos então relevante destacar nesta fase inicial do trabalho, as características de alguns projectos de outros media já devidamente consolidados no mercado da arte, como a animação e o cinema, mas que também eles são referências do passado.

\section{Poética formal da animação}

Tradicionalmente a acção cinematográfica é representada por espaços onde se centra a narrativa ou a atuação de personagens, sendo um dos aspectos centrais do "cinema". A transformação do espaço promove que os eventos cinematográficos possam evoluir ao longo da narrativa e, de igual modo, apresentam um novo lugar para o espectador explorar. Na animação o espaço parece apresentar fronteiras menos definidas e essa liberdade oferece um caminho exploratório para o desenvolvimento dos guiões ou de uma animação mais performativa. Veja-se como em Duck Amuck (Chuck Jones, 1953) a interação da personagem é realizado com as constantes transformações do cenário, como Tom salta do cenário para a película em Tim Tom (Romain Sefaud e Christel Pougeoise, 2003), como a transição de cenários é feita por metamorfoses em The Street (Caroline Leaf, 1976), como a curiosa combinação de espaço tridimensional com formas bidimensionais de Flatworld (Daniel Greave, 1997) ou as transições agressivas de diferenciados cenários ou perspectivas em Nocturna Artificialia: Those Who Desire Without End (Brothers Quay, 1979), ou o modo como o espaço e as personagens se fundem em A Estória do Gato e da Lua (Pedro Serrazina, 1995). Por mais diferentes que sejam estes exemplos aqui retratados, o que lhes é comum é o facto de evocarem uma ligação narrativa do animador ao espectador, através dum contínuo espaço animado que tão facilmente se fragmenta como se agrega.

Em The Metamorphosis of Mr Samsa (Caroline Leaf, 1977), cerca do segundo minuto do filme, confere-se que a edição é feita através da metamorfose do desenho, fazendo com que os diferentes planos se interliguem através de movimento. Trata-se de um plano sequência que salta de escala em escala através das transformações das formas representadas por areia. Verificamos que um trabalho de edição com recurso ao uso de transição por dissolve resolveria alguns dos cortes, mas perderiam todo o encanto "mágico" da animação das formas que se transformam nesta passagem de plano para plano.

A curta A Estória do Gato e da Lua (Pedro Serrazina, 1995) revela como a ideia de construção e manipulação do espaço fascina este animador. Explorando o dentro e fora-de-campo, o espaço limitado pelas quadrículas da banda desenhada, mas que simultaneamente geram novas dimensões através da composição numa página. 
Serrazina exibe como a animação não está necessariamente associada às personagens de figura humana ou animal, pois o espaço, as texturas ou movimento gerado podem ser a personagem principal. Serrazina parece interessar-se no modo como o espaço da página, da moldura ou das entidades representadas podem se formar, diluir, reverter e integrar num movimento continuo. Tal como as vinhetas da banda desenhada que não são apenas os limites do desenho, mas sim parte integrante deles. As personagens interagem com as vinhetas que, na composição da página, não limitam os enquadramentos facultando a liberdade narrativa de as quebrar, misturar ou eliminar. Esta possibilidade de "saltar para fora" da moldura, de transformar o espaço inscrito em circunscrito é evidente nas metamorfoses desta curta.

Esta estratégia deste animador evoca a poética da representação das formas animadas a que José-Manuel Xavier se refere e que permite que o espaço se relacione de uma forma peculiarmente interessante com os objectos ou personagens que o habitam (Xavier, 2007: 32). É como se não existisse uma fronteira definida e o espaço possa ser a própria matéria dos objectos representados. A metamorfose animada remete assim a representação das figuras para um único lugar, do qual tudo the pertence ou the é retirado. Como se tratasse de um espaço vivo, ao que Aylish Wood se refere como reverberating space por promover a formação de figuras que emergem como ecos distorcidos do som original (Wood, 2006: 138). Esta característica resulta do sentido estético ou objectivo narrativo de cada objecto animado, que é estranha à imagem real do cinema ou à simulação física videojogos e, por conseguinte, evidencia a animação como um media consolidado, com características particulares e disruptivas com outras formas de comunicação.

\section{Videojogos e a maturidade da animação?}

A animação é o resultado da conjugação de vários fotogramas que de um modo isolado podem ser ilustrações menores, mas quando associadas sequencialmente se revelam fascinantemente atractivas. O que pretendemos salientar é o facto de um trabalho de desenho, ilustração ou pintura é normalmente comtemplado com tempo, como uma imagem que é apresentada num determinado espaço de representação e onde o espectador pode deliciar-se em qualquer pormenor da obra durante o período de tempo que quiser disponibilizar. Ora, a animação é o resultado da projecção de sequências de desenhos (fotogramas) que impossibilitam a observação de cada imagem isoladamente, produzindo-se assim a obra animada que nasce na ligação entre os fotogramas ${ }^{2}$. A qualidade dos desenhos é aparentemente irrelevante, pois o que conta é a imagem-movimento que cria uma nova dimensão artística (Deleuze, 2009: 27). A referência à imagem-tempo de Deleuze ajuda-nos a explicar como os fotogramas animados promovem um novo movimento que pode não se relacionar directamente com 
os fotogramas antecedentes ou com que os sucedem. Verificam-se diferenças importantes entre o cinemático e o animático no modo como o espectador se apresenta disponível para aceitar novos movimentos que surgem de modo descontínuo de plano para plano. Veja-se por exemplo como a composição multi-perspectivada é tão bem aceite na animação, mesmo se sujeita a erros técnicos que se tornam insuportáveis nos filmes de efeitos visuais ou em videojogos. Um erro visual não pode ser revelado no cinema clássico, tal como uma falha de continuidade, ou uma personagem mal recortada de um fundo azul ou uma paisagem que está incompleta. Na animação a falta de continuidade visual ou a imperfeição da representação em desenho é frequentemente uma busca estética ou narrativa e, por conseguinte, os fotogramas não têm de ser concebidos com o rigor da representação clássica da perspectiva que é capturada por uma câmara de filmar.

A liberdade que o cinema de animação apresenta através dos mais diversos conteúdos publicados ao longo da sua história, colocam-no então num estado de maturidade a que a indústria de jogos ainda não atingiu. Seja por dificuldades técnicas do domínio informático, pela juventude dos agentes desta indústria ou pelas possibilidades ainda por explorar, que são ainda poucos os exemplos de jogos que se apresentam num registo visual ou narrativo mais disruptivo.

Por esta razão, destacamos neste trabalho alguns jogos que reflectem esta procura visual de assumirem o erro, a imperfeição do real, ou a efemeridade do tempo presente. As assumidas falhas visuais de Old Man Journey na sobreposição das camadas do desenho ou estilo gráfico de Serial Cleaner, remetem para o reino da animação. Serial Cleaner é um jogo top-down com uma estética muito precisa, num claro registo dos anos 70. Os avatares polidos visualmente de forma simplificada, dependendo da sua orientação no espaço de jogo, podem ter fisionomias diferentes, ora com sapatos ou sem. Esta liberdade contrasta com a procura de realismo de jogos mainstream e torna-se diferenciador precisamente por este contraste. Pelo facto de ter inúmeras referências com motion graphics, fashion design ou género cinematográfico dos anos 70, não podemos deixar de o destacar pela sua disrupção com os jogos do mesmo género do período actual.

De igual modo, a plasticidade visual de The Adventures of Prince Achmed (Lotter Reiniger, 1926), Berlin: Symphony of a Great City (Waltter Ruttmann, 1927) ou L'ldée (Berthold Bartosch, 1932) apresentam-se de modo muito alternativo à animação da época. Se verificarmos os cartoons e BD publicados na Revista Punch ou jornais da época nos Estados Unidos e Europa, facilmente se reconhece as ligações estéticas dos personagens desenhados com os seus congéneres animados. Krazy Kat (Otto Mesmer), Oswald the Lucky Rabbit (Ubbe Iwwerks, 1927) Bonzo the Dog (George Ernest Studdy), Little Nemo (McCay) ou Kapten Grogg (Bergdahl, 1917) são alguns dos exemplos de personagens cartoon que migraram directamente para o cinema de animação. 
A produção norte-americana forçou o aparecimento de inúmeras personagens que saltaram do papel para o desenho animado, criando assim um novo nicho de mercado da imagem em movimento e que se definiu nos momentos iniciais pela construção de pequenas narrativas baseadas em gags, numa clara tradição cartoon que também foi visível nos primeiros filmes de imagem real. Estas apropriações de géneros cinematográficos ou de personagens já consolidadas revelavam a juventude da animação enquanto media muito provocado por questões comerciais ou por alguma falta de criatividade. Esse rasgo genial estava presente, mas mais evidente através das obras disruptivas de Reiniger, Rutmann ou Bartosh.

A história repete-se e no caso dos videojogos ainda não se atingiu um período de maturidade, apesar dos diversos projectos exploratórios no campo da interactividade que desde a década de 50 abriram caminho para novos ensaios em torno das artes em geral. Vivemos um emergente período de experimentação no campo narrativo e visual dos videojogos, mas de modo geral, muitos dos jogos recuperam medias antigos para solucionar problemas do domínio estético ou tecnológico sem uma real preocupação de inspiração artística. Os criadores do jogo Prince of Persia (Brøderbund, 1988) recuperaram através da rotoscopia os movimentos de Errol Flynn no filme The Adventures of Robin Hood (Michael Curtiz e William Keighley, 1938), para conseguir apresentar o realismo no movimento dos personagens e actualmente, as modernas tecnologias de motion capture continuam a fazer o mesmo apesar de existirem diversos exemplos disruptivos no ramo das artes que ainda não são aproveitados pela indústria.

As primeiras técnicas de motion capture deixaram-nos um delegado visual muito rico - a cronofotografia. As sobreposições de Étienne-Jules Marey que apresentam deslocações de pessoas ou líquidos fragmentados no tempo, serviram para estudos do movimento, contudo o seu resultado final, em termos visuais, é virtualmente rico, criativo.
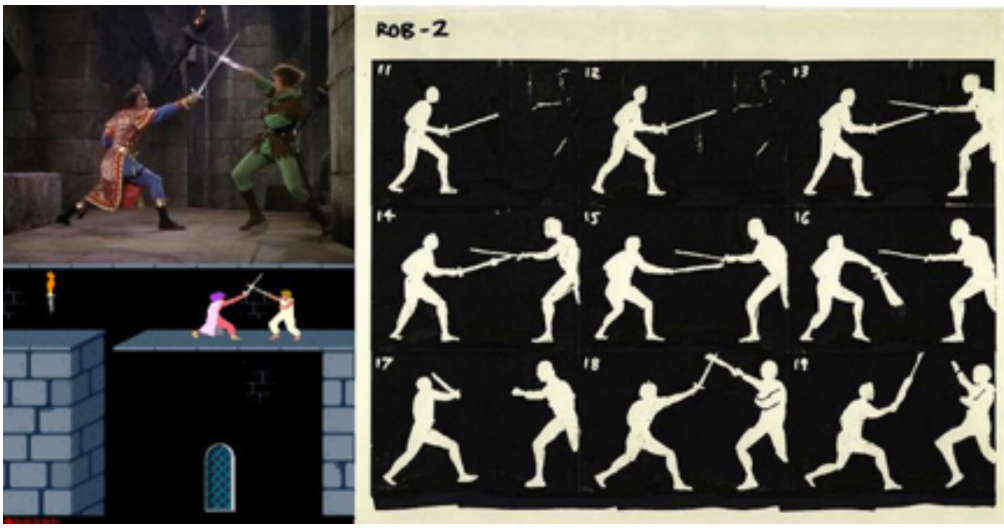

Figura 1. Rotoscopia dos combates de The Adventures of Robin Hood (Warner Brothers, 1938) e movimentos de Prince of Persia (Brøderbund, 1988). 


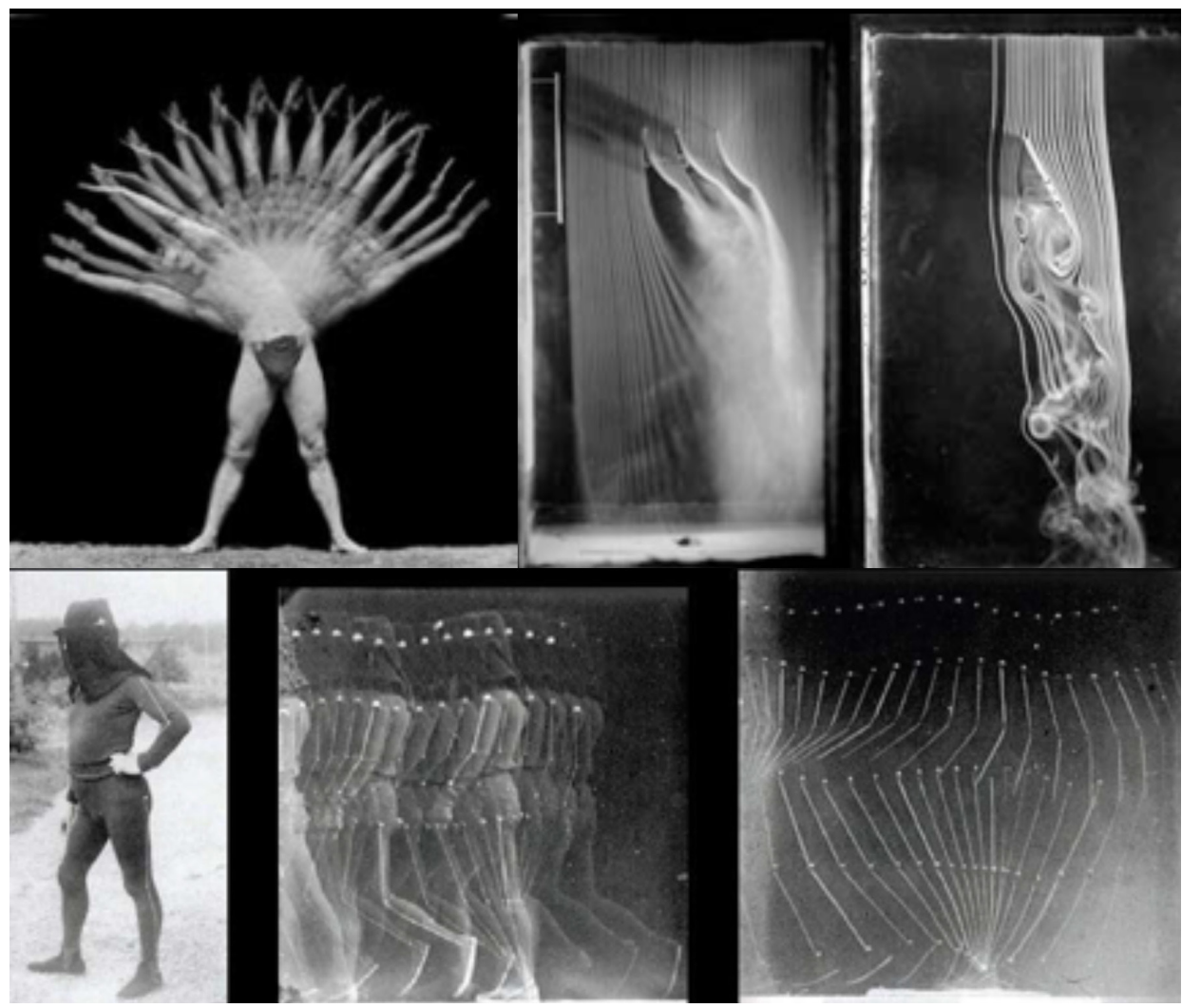

Figura 2. Cronofotografia e fato de captura de movimentos (1883) de Étienne-Jules Marey.

O resultado final da cronofotografia é um mapeamento bidimensional de um movimento que pode ser aproveitado para a maquetização de qualquer outro novo produto. Por exemplo, ao reproduzirmos esta técnica num conteúdo vídeo, como Norman McLaren o fez em Pas de Deux (1973) ou Marcel Duchamp pintou em Nude Descendre l'escalier, no.2 (1912) o media torna-se opaco ao mostrar que o vídeo é assente numa sucessão de fotografias, mas simultaneamente surge uma nova forma estética, assumidamente alternativa e disruptiva em relação aos habituais usos do motion capture. Made by Humans (2012) é uma apropriação recente desta técnica tal como é a versão tridimensional da cronofotografia em Human Movement Through Space (Peter Jenson).

O que pretendemos também argumentar é que uma das evidências da imaturidade do media videojogo é o frequente recurso ao mocap para simplesmente obter realismo nos personagens, mimetizando outros medias para uma aproximação ao real. Made by Humans ou Human Movement Through Space são apropriações de outros media mas com resultado claramente demarcado da referência original. A indústria de videojogos 
ainda se mostra muito dependente de outros media para se aproximar deles e são ainda poucos os exemplos tímidos em que procura evidenciar as suas características particulares para se demarcar como um meio alternativo.

\section{Conclusão}

Em formato de trabalho futuro, desafiamos os produtores, escolas e entusiastas de jogos a afastarem-se da "fisicalidade da programação", para procurarem no erro, na imperfeição, no acidente a potencialidade criativa da arte para a criação de novos espaços de interacção. A reverem como a pintura evoluiu com o aparecimento da fotografia, como a música se adaptou aos novos sintetizadores, como a animação luta com as limitações da modelação 3D, para de forma colaborativa procurarem o espaço de jogo onde o erro e o inesperado surgem de forma natural.

Desafiar os alunos a utilizar meios analógicos para serem surpreendidos com o erro, gera criatividade, de igual modo, fazer triangulações entre diversas áreas do saber, promove a originalidade e o progresso. Exemplificamos esta afirmação com o exemplo DELLI (Design Lusófona Lisboa) ${ }^{3}$ por ser um espaço criativo de interacção entre áreas científicas que normalmente não se misturam no processo criativo. Um dos mais recentes eventos deste hub criativo, foi a Neuro Game Jam que reuniu neurocientistas, designers, game designers e programadores para responderem a um conjunto de questões, focadas na precisão, capacidade analítica, emoção, imersão e entretenimento. O resultado desta colisão foi uma importante amostra de demos, sendo que a obra vencedora The Third Eye of a Gazelle ${ }^{4}$ (Eva Vital, Isaque Sanches e João Costa, 2018) ilustra plenamente como a fusão de uma equipa multidisciplinar num espaço adequado, promove a originalidade artística, mesmo quando se procura a execução de um projecto com fins exclusivamente científicos.

\section{Endnotes}

1 «Volete dunque sprecare tutte le forze migliori, in questa eterna ed inutile ammirazione del passato, da cui uscite fatalmente esausti, diminuiti e calpesti?». Cf. http://www. classicitaliani.it/futurismo/manifesti/marinetti_fondazione.htm (última consulta a 12 de Outubro de 2013).

2 A famosa frase de Norman Mclaren foi citada por Charles Solomon: «Animation is not the art of drawings-that-move, but rather the art of movements-that-are-drawn. What happens between each frame is more important than what happens on each frame.» (Solomon, 1987: 11).

3 Cf. http://www.delli.pt/ (consultado em 15/5/2018)

4 Cf. https://www.youtube.com/watch?v=OAfmLe-yKTK (consultado em 15/5/2018) 


\section{Referências Bibliográficas}

GoldBerg, D. e Larsson, L. (2014). Mincraft: The real inside story of Markus "Notch" Person and the gaming phenomenon of the century. Virgin Books: London.

Deleuze, G. (2009). A Imagem-Movimento: Cinema 1. Lisboa: Assírio \& Alvim.

Konzack, L. (2008). Videogames in Europe in Mark J. P. Wolf (Org.) The video game explosion: a history from Pong to Playstation and beyond. Greenwood Press: Westport.

Marques, S. (2007). Cópia e Apropriação da Obra de Arte na Modernidade. Tese de Mestrado, Lisboa: UNL-FCSH

Therrien, C. (2008). Graphics in Video Games in Mark J. P. Wolf (Org.) The video game explosion: a history from Pong to Playstation and beyond. Greenwood Press: Westport.

Marinetti, T. (1909). Manifesti Futuristi in Biblioteca dei Classici italiani di Giuseppe Bonghi [Disponível em: http://www.classicitaliani.it/futurismo/ manifesti/marinetti_ fondazione.htm, consultado em 12/4/2018].

Solomon, Charles (1987). The Art of The Animated Image, An Anthology. Los Angeles: The American Film Institute.

Wood, A. (2006). "Re-Animating Space" in Animation: an Interdisciplinary Jornal, 1 (2). Londres: SAGE. Xavier, J. (2007). Poética do Movimento. Lisboa: Edições da Monstra.

Filipe Costa Luz

Hei-Lab (Human Enviornment Interaction Lab, Universidade Lusófona de Humanidades e Tecnologias - Lisboa, Portugal

Email: filipe.luz@ulusofona.pt Orcid: https://orcid.org/0000-0002-3608-8417

Correspondência

Filipe Luz

Universidade Lusófona

Campo Grande, 376 1749-024 Lisboa

Data de submissão: Janeiro 2018

Data de avaliação: Março 2018

Data de publicação: Julho 2018 